\title{
Research on Experimental Teaching Reform of Railway Engineering under the Training of International Students
}

\author{
Zhiping Zeng ${ }^{1}$ Bin Yan $^{{ }^{*}}$ Jossph Eleojo Victor ${ }^{1,2}$ Zhihui Zhu $^{1}$ Weidong Wang ${ }^{1}$ Ping Lou $^{1}$ \\ Wei Li ${ }^{1}$ \\ 1. School of Civil Engineering, Central South University, Changsha, Hunan, 410075, China \\ 2. Department of Civil Engineering, Faculty of Engineering, Ahmadu Bello University Zaria, Kaduna State, 800242, \\ Nigeria
}

\section{ARTICLE INFO}

\section{Article history}

Received: 24 December, 2020

Revised: 18 January 2021

Accepted: 3 February 2021

Published Online: 16 April 2021

\section{Keywords:}

International students

Railway engineering experiment

Teaching reform

\begin{abstract}
The railway engineering major shows extremely strong applicability, with the internationalization of railway engineering teaching and communication, how to solve the problem of cultivating the international students of the railway engineering major experimental teaching is a core problem that the railway engineering majors in universities need to solve at this stage. Through reform, a new type of experimental teaching system for railway engineering specialty was constructed, that is, the experimental course system and content system determined by the international students training program were taken as the core, the construction of teachers, experimental facilities, practice bases and other conditions as the basis, and the system construction and operation organization to build an organic whole composed of four elements for guarantee. It is closely integrated with the theoretical teaching system and relatively independent. It guarantees the realization of the goal of international students training. And it can integrate and optimize the experimental teaching links, content, methods and evaluation system, and build a "gradual experimentprofessional experiment-comprehensive experiment" progressive gradient experiment teaching system. Form a benign pattern of collaborative training of laboratories, practice bases and scientific research bases, mutual promotion of teaching and scientific research, and effectively promote the improvement of students' experimental innovation ability.
\end{abstract}

\section{Introduction}

With the rapid development of the whole world's economy, urbanization is getting faster and faster, which has brought huge traffic pressure. Urban rail transit has a significant role in alleviating traffic congestion. Therefore, in recent years, urban rail has developed rapidly, and various cities across the country have successively opened new urban rail lines ${ }^{[1]}$. At the same time, the whole world's higher education is constantly changing from elite education to mass education. Cultivating international students to serve regional economic development has become a major choice in the transformation and development of colleges and universities. How to cultivate international

*Corresponding Author:

Bin Yan,

School of Civil Engineering, Central South University, Changsha, Hunan, 410075, China;

E-mail:1877043690@qq.com. 
students and how to cultivate international students can meet the needs of regional economic development is a series of problems to be solved in the development process of colleges and universities at this stage. Nowadays, many colleges and universities have established railway engineering majors. As an engineering major, they should pay special attention to the organic integration of theory and experiment in order to cultivate international students with good basic theory, related skills, and certain experimental and innovative capabilities ${ }^{[2]}$. This shows that it is of great practical significance to study and explore the reform of the railway engineering experimental teaching under the training of international students.

At present, the international students training model of higher education in our country is mainly the theoretical international students training model. The theoretical teaching of this international students training model occupies the absolute dominant position, which is in contradiction with the training goal of international students ${ }^{[3]}$. The main performance are as follows:

(1) The experimental teaching curriculum system and the experimental teaching content system have not been systematic and complete, and are always in a subordinate position. The proportion in the overall curriculum system is generally light, and the proportion of credit hours is generally below $20 \%$, which is far from the goal of $30 \%$.

(2) The content and form of experimental teaching have not kept pace with the times, the content is outdated, the form is single, the teaching methods and teaching methods are relatively backward, and lack of independence and innovation.

(3) The operation, supervision, assessment and evaluation mechanism of the experimental teaching link has not been effectively established. There are outstanding problems in the implementation process of the experimental teaching link, such as irregular operation, inadequate supervision, unscientific assessment, and inadequate evaluation.

(4) The existing faculty structure and level contradict the research international students training requirements. At present, the vast majority of teachers in colleges and universities are directly engaged in teaching after graduation, and then go out to enter the school. The theoretical level is relatively high, but the experimental experience and engineering experience are generally lacking, and it is difficult to be competent for experimental teaching instructors.

In response to these problems, many domestic universities have carried out active reforms and explorations. Through years of research and experiment, the experimental ability of college students has been strengthened, but the effect is not obvious, and the impact is small. The reasons are as follows: First, the results of the research are relatively fragmented, and it is more difficult to implement it; second, many methods and suggestions are obtained by key universities using their own resource advantages and school characteristics, and are not applicable to other universities, especially research-oriented places.

The experimental teaching system is a general term for the contents of the experimental teaching activities carried out to achieve the goal of personnel training, the related management carried out and the conditions supporting these activities. Specifically, the experimental teaching system is based on the experimental courses and experimental content determined by the international students training plan, based on the construction of experimental teaching teachers, laboratory construction, and construction of off-campus practice bases, and is managed by the three levels of school, college, and department. And supervision to ensure the integrity of the system. How to build a professional experimental teaching system that adapts to the development needs of modern higher education and adapts to the research-based training model, and cultivate research-oriented professionals with a solid theoretical foundation, broad professional knowledge, strong engineering experimental capabilities, and innovative capabilities, It has become an important subject of professional teaching reform in colleges and universities. We took the railway engineering specialty as an example, discussed the methods and methods of experimental teaching reform and optimization, explored the training mode and operating conditions of research-oriented undergraduate talents, and constructed a new experimental teaching system for research-oriented international students training.

\section{The Necessity of International Students Training}

Under the background of global integration and continuous development of market economy, the cultivation of international students is a major goal of college education. With the gradual deepening of the whole world's reform and opening up, the whole world's higher education system has developed from elite education to mass education, aiming to comprehensively improve the comprehensive quality of our nationals. Modern colleges and universities attach great importance to the cultivation of international students, which is an inevitable requirement to comply with the development of the times. Nowadays, the market economy is becoming more and fiercer, and various industries are competing for development. As a 
foundation of national construction, the railway engineering industry is also constantly reforming and innovating, changing from the traditional single business model to a comprehensive business model. The difficulty of engineering in response to the needs of social construction is increasing day by day. The scale of projects such as large-scale subway construction and high-speed railway construction is continuously expanding, and the construction difficulty is gradually increasing. It's getting tougher. With the innovation of various theories and academic knowledge, railway engineering professionals are required to not only master their own basic theoretical knowledge, but also have certain innovative and experimental capabilities. Therefore, colleges and universities are required to continue to promote effective innovation of international students training methods, rely on the organic integration of existing educational theories and new educational ideas, continue to study and actively explore new ways of training talents ${ }^{[4]}$.

\section{Main Problems in the Experiment Teach- ing of Railway Engineering under the Train- ing of International Students}

At this stage, there are still a series of problems in the training of railway engineering international students, and the main manifestations are as follows: First, the training goals of railway engineering international students lack clarity. On the issue of cultivating international students in railway engineering, most of them are formal and fail to form the school's own characteristics ${ }^{[5]}$. Even though some colleges and universities set their own international students training goals as research-oriented, they have not made an effective distinction between research-oriented, technical-oriented, and compound-oriented talents. The goal of railway engineering research-oriented international students training is not clear, which will adversely affect the growth of students. Second, the teaching system for the training of international students in railway engineering is not perfect. At this stage, the training of railway engineering professionals in colleges still has the problem of emphasizing theory and ignoring experiments. Even though the corresponding experimental teaching links are set in the course teaching process, under the influence of factors such as teaching funds and teaching conditions, most of them are useless and not carrying out experiment teaching such as simulation teaching, case teaching, and school-enterprise cooperation teaching well, which will adversely affect students' experimental ability training.

\section{The Reform Strategy of Railway Engineer- ing Experiment Teaching under the Training of International Students}

\subsection{Clarify the Training Target of Railway Engi- neering Talents}

International students training needs to consider all aspects. On the one hand, the core ideas of the railway engineering major and the original intention of professional teaching must be considered; on the other hand, the current market development needs should be considered, fully integrated with the actual situation of the university; Cultivate international students who can master basic theoretical knowledge of railway engineering and be able to experiment. High-quality talents are international students who can skillfully apply railway engineering expertise in social construction. They are different from other types of talents. The main feature of international students is that they do not need to have rich professional theoretical knowledge or master skilled skills. It should be more inclined to the experimental application ability of professional knowledge in the construction of actual railway projects ${ }^{[6]}$. In other words, international students are those who can carry out technical work in various departments such as engineering design in railway engineering. Therefore, the ultimate goal of railway engineering professional training is to train international students to meet a series of requirements in the development of modern social engineering.

\subsection{Promote the Reform of Teaching Courses and Teaching Systems}

In order to achieve the goal of cultivating international students in railway engineering, educators must innovate teaching concepts, transform the traditional teaching-centered teaching model, give play to the role of students as the main body of teaching, and give full play to students' subjective initiative in the creative learning process: First, build and improve the curriculum system. The course system is mainly composed of course objectives, course content, course structure, etc. It is an indispensable part of course teaching. For the construction of the railway engineering professional curriculum system, the teaching content should be promoted in an orderly manner, emphasizing experimental teaching, comprehensively building a diversified teaching platform, and forming a new curriculum system for professional electives, extracurricular experiments, vocational skills and technological innovation. Second, scientifically set teaching tasks and goals. Combine with the needs of the industry, optimize the cur- 
riculum, and promote the effective transfer of information to knowledge and ability. In terms of teaching tasks and goal setting of basic knowledge of railway engineering, students can develop their ability to think independently, and they can effectively apply theoretical knowledge and learn to apply basic knowledge to solve practical problems. In terms of professional skills teaching tasks and goal setting, consolidate the corresponding learning software of students, combined with modern information and software application technology, to achieve the proficient application of cad, PKPM, AUTOCAD and other software to improve students' innovative awareness, independent problem-solving skills. In addition, under the background of the current information age, in addition to basic expansion, the railway engineering major should also create a good application platform to help students realize the transformation of "information-knowledge-ability".

\subsection{Strengthen the Cultivation of Innovation Abil- ity, Experimental Ability and Engineering Aware- ness}

The cultivation of international students in railway engineering should strengthen the cultivation of innovative ability, experimental ability and engineering awareness, specifically: first, give full play to the subjective initiative of professional learning and cultivate the spirit of innovation $^{[7]}$. Teachers should start from the teaching content, teaching methods and other aspects, change the traditional boring theory teaching, the teaching material knowledge is not connected with the actual, mechanical indoctrination teaching form, pay attention to discovering the advantages and disadvantages of students in learning, and encourage students to express their personal opinions, Ideas, scientifically guide students to understand and master professional courses. For example, with the continuous development of information technology, in the teaching process of professional courses such as "Track Engineering", "Railway Route Design", etc., teachers can use the Internet platform to analyze the learning effect of students, just like relying on BB network teaching platform, through learning courses anytime, anywhere, watching teaching courseware videos, completing homework tests, etc. discovers the advantages and disadvantages of students, so as to promote more effective and targeted teaching content and teaching methods for students. Secondly, strengthen experimental teaching and cultivate experimental ability.

To optimize the content of experimental teaching and improve the quality, teachers should encourage students to take the initiative to learn, take the initiative to ask questions, actively collect learning materials, take the initiative to carry out experimental learning, and introduce a variety of evaluation standards to effectively protect students' learning effects. Finally, clarify industry regulations and cultivate engineering awareness. Teachers should strengthen the introduction of case teaching content, combined with actual engineering problems, through engineering language expression, create a strong engineering atmosphere, encourage students with relatively high learning levels to participate in the research and practical engineering design of related topics, and help students improve their effective understanding of the nature of the industry to clarify professional regulations and establish a correct concept of professional ethics, so that students can quickly integrate into the social work environment.

\section{Research Methods}

\subsection{Research}

First, through surveys, we visited a number of colleges and universities specializing in railway engineering in and outside the province, especially local similar universities, to gain a deeper understanding of their effectiveness and experience in the construction of railway engineering majors, and to understand their lessons, deficiencies and reform plans to comprehensively collect data on international students training programs, curriculum syllabus, faculty construction, management system and operation mechanism of railway engineering majors in similar universities in and outside the province, and conduct systematic research and analysis on its curriculum system, especially experimental curriculum system, etc. So as to provide a reference for the revision of the training plan of railway engineering professionals and the reform of experimental teaching in our school. Secondly, in-depth investigations visited railway bureaus, subway companies, railway design institutes, The whole world Railway Engineering Bureau and other enterprises, interviewed management and technical personnel at all levels to investigate their needs for the knowledge, ability and quality of railway engineering graduates, and recruited these employers summarize, research and analyze the opinions and suggestions on teaching, especially experimental teaching, so as to provide a basis for the revision of our school's international students training program and the reform of the experimental teaching system ${ }^{[8]}$. Third, in-depth study of the development status of domestic and foreign higher education, especially the current status and development trends of higher engineering education, study and research on the reform opinions of the national education mid- and long-term development plan, and the guidelines for the teaching of railway engineering developed by the Railway Engineering Professional Steering Committee, carefully 
look for the current problems in the training of railway engineering professionals, analyze and study the causes and root causes of the problems, and form reform ideas.

\subsection{Constructing an Experimental Teaching Sys- tem for the Cultivation of International Students}

On the basis of learning, investigation and research, first of all, through the holding of seminars, reform program demonstration meetings and other forms, the research will clarify the international students training goals and training specifications of our university's research-oriented railway engineering major, and revise the professional international students training programs according to the training goals and specifications. Secondly, the two aspects of theoretical teaching and experimental teaching should be coordinated, the experimental teaching course and the experimental content should be integrated and optimized, the experimental teaching linking to theoretical teaching should be stripped away as far as possible, an independent experimental teaching course should be set up, and the experimental teaching course system should be built in parallel with theoretical teaching. Finally, through formulating experimental curriculum syllabus, establishing experimental teaching management system, strengthening the construction of experimental teaching conditions, strengthening experimental teaching faculty and other measures, constructing experimental teaching operation guarantee system, so as to ensure the realization of training goals.

\subsection{Experiment and Continuously Optimize the Experimental Teaching System}

In response to the new experimental teaching system, positive and stable reform measures were taken to implement it. The reform of experimental teaching involves a wide range. In the experiment, internship, course design, experiment report and other links, first of all, choose the more mature part to carry out the reform pilot, and gradually expand and promote the use of points on the basis of gaining experience. Identify the problems in the pilot reform in time, summarize the successful experience, and continuously improve and optimize the experimental teaching system.

\section{Reform Plan Design}

6.1 Overall Planning of Two Courses System of Theoretical Teaching and Experimental Teaching, Revising the Training Plan for Railway Engineering Professionals

Theory teaching and experiment teaching are relatively independent, but also interrelated and inseparable. Therefore, it is necessary to carry out overall reform of the theory teaching system and experiment teaching system in accordance with the requirements of the railway engineering research international students training objectives and training specifications. In the reform process, it is necessary to emphasize that the two are relatively independent and self-contained, but also to focus on the main line of engineering experiment and technology application ability training, close contact and mutual penetration, and jointly complete the task of professional knowledge transfer and engineering experiment ability training. Adjust the curriculum system, separate part of the experimental teaching from theoretical teaching, and set up independent experimental courses. Increase the proportion of experimental teaching and increase the hours and credits of experimental courses.

\subsection{Coordinate Each Experimental Teaching Link and Build A Gradient Experimental Teaching System of "Basic Experiment-Professional Exper- iment-Comprehensive Experiment"}

The experimental course system of the railway engineering specialty includes experiments, internships, course design, experiment reports, professional competitions, scientific and technological innovation activities and other basic links. It needs to be coordinated and arranged reasonably, and to construct the "basic experiment-professional experiment-comprehensive experiment" gradient experiment course and content system ${ }^{[9]}$.

(1) It is necessary to reconstruct the experimental course system and optimize the experimental teaching content. It is necessary to break the pattern of opening experiments according to courses, and integrate the affiliated experiments of the courses with strong relevance to set up independent experiment courses. According to the four steps of basic experiment, professional basic experiment, professional experiment and comprehensive experiment, train and continuously improve students' hands-on and innovative skills. Try to eliminate validating and demonstrating experiment items in experiment courses, and add comprehensive, design, innovative and open experiments, and strive to change the past practice of consolidating classroom knowledge and conducting experiments in order to improve knowledge, ability and quality. The cultivation of the culture is integrated, and the direction of ability cultivation is mainly changed.

(2) We must build a new practice teaching system. Railway engineering professional internship generally includes professional recognition internship, engineering survey internship, production internship, graduation in- 
ternship, etc. Internship is an indispensable experimental teaching link for railway engineering majors. However, due to environmental hardships, safety risks, relatively limited internship resources and the impact of postgraduate entrance examination in the process of engineering project research, the professional internship of railway engineering faces many difficulties and problems. The reform of internship teaching should combine the construction of on-campus and off-campus internship bases, combine traditional internship methods with modern virtual simulation internships, combine internships with job search and employment, combine full-time teacher guidance with enterprise part-time teacher guidance, and combine internships. The combination of fixed time schedule and flexible schedule. Through the overall design, to meet the requirements of internship purposes.

(3) Curriculum design should be carried out with a systematic thinking. The course design of the railway engineering specialty is divided into railway line planning and design, and track structure course design. The reform of the course design link should be unified, coordinated, and comprehensively considered, and strive to change the current situation of the course design based on a single course, and realize the change to several interrelated courses for joint course design. The instructor is guided by the single course teacher to the course group teachers jointly guide the transformation. Strengthen the relevance and coordination between each course design. Each course design should not only aim at the course, but also consider the comprehensive training of the entire course design system on related skills.

(4) Teach students according to their aptitude, and conduct experimental reports according to employment orientation. First of all, the title of the experiment report should not be single, but should have diversity for students to choose. Topics such as track design, line design, and research papers can allow students to choose according to their own strengths, abilities, hobbies, and future study or employment direction. Secondly, according to the needs of the experimental report, hiring track structure designers, line engineers, etc. of the track design department to participate in the experimental report or graduation thesis guidance can not only improve the practicality of the design, but also help to improve the level of the experimental report guidance of full-time teachers.

(5) Build an innovation training unit for college students. In order to embody the principle of the harmonious development of railway engineering professionals 'knowledge, ability and quality, special emphasis should be placed on the cultivation of college students' innovative thinking, innovative methods and scientific research and innovative capabilities. In accordance with a stepby-step approach, innovative training is planned from the lower grades to the upper grades, using the experimental system as the carrier, and carrying out innovative training in experiments, internships, design, and social experiments; selecting appropriate knowledge departments and experimental links, formulating innovative thinking, The training methods of innovative methods and innovative capabilities are constructed as innovative training units. By absorbing some of the specialty students to participate in the teachers 'scientific research projects, cultivate the basic literacy of students' scientific research; through the form of tutor system and student professional associations, organize students to carry out small inventions, small production activities, participate in professional competitions, and stimulate students 'innovative spirit Actively participate in enthusiasm.

\subsection{Formulate the Experimental Curriculum Syl- labus, Determine the Content and Requirements of Each Experimental Teaching Link}

By formulating a revised curriculum syllabus, clarify the status and role of each experimental course in the professional teaching plan, determine the basic tasks and requirements of the course, key and difficult courses, assessment methods, etc. While developing the syllabus, prepare and the experimental teaching documents supporting the syllabus, such as various experimental teaching task guides, etc., ensure that every experimental teaching operation has chapters to follow and norms and order.

\subsection{Construct a Systematic and Complete Exper- imental Teaching Management System to Ensure the Effective Operation of Experimental Teaching Planning, Implementation, Supervision, Evalua- tion, and Feedback}

The cultivation of high-quality international students is a very complicated project research project. To achieve the effect of experimental teaching, not only must we design a "blueprint" for personnel training, but also to study the experimental teaching operation system and mechanism, from team building, the construction of laboratories and experimental bases, experimental teaching content, teaching methods and methods, evaluation and personnel allocation mechanisms are systematically reformed, supplemented by strong restraint and incentive measures. First of all, according to the characteristics of experimental teaching, a set of management system that conforms to the operating rules of experimental teaching should be developed to ensure that each experimental teaching link 
is effectively implemented according to the teaching plan; secondly, an experimental teaching management system should be built to establish horizontal collaboration between schools, colleges, localities, and enterprises. The experimental teaching management framework of the linkage of colleges, departments, teachers and students to ensure the effective operation of experimental teaching ${ }^{[10]}$.

The design of the above reform plan can be summarized into four aspects: "core of curriculum content"'“condition guarantee dimension" "system guarantee dimension", and "organization guarantee dimension" for the experimental teaching of railway engineering. The construction of the experimental teaching curriculum system and content system is the core of the reform plan design; the construction of the laboratory and the construction of the practice training base inside and outside the school are the conditions for the implementation of the plan; the establishment of a sound experimental teaching rule system is the guarantee for the implementation of the plan and the rationalization of the experiment. The teaching management system and the strengthening of the teaching team of experimental teaching are the guarantee for the reform to achieve practical results.

\section{Outlook of Reform Results}

\subsection{Build a High-Level Engineering, Dual-Teach- er, Innovative, Professional and Combined Teach- er Team}

Through training in survey, study, discussion, research, etc., project team members can understand the current situation and development trend of higher education at home and abroad, establish advanced higher education teaching concepts, become familiar with and master advanced teaching methods and teaching methods, and learn from other universities The advanced experience of running a professional school and understanding the actual needs of society and enterprises for talents' knowledge, ability and quality will help them improve teaching and further improve the level of education and teaching. By sending young teachers to enterprises for engineering experiment training, participating in enterprise project evaluation, engineering design, engineering construction, joint public relations of scientific and technological problems, etc., so as to enhance teachers' engineering awareness, engineering ability and innovation ability. By hiring track construction and design enterprise engineers as part-time teachers, teaching students relevant professional courses, and serving as instructors for experimental courses, building a high-level teacher team with certain engineering experience and a combination of full-time and part-time teachers.
7.2 Constructing an Experimental Teaching Management System and Operating Mechanism that Guarantee the Effective Implementation of the Research-Oriented International Students Training Model

By formulating systematic experimental teaching management systems, such as undergraduate academic mentoring system, experimental teaching supervision system, laboratory open management system, etc., it provides system guarantee for the smooth development of each experimental teaching link. Through the construction of the experimental teaching organization system, straighten out the experimental teaching management, and establish an experimental teaching management framework in which schools, localities, and enterprises cooperate and collaborate, and colleges, departments, teachers, and students work together. Ensure that everything from the formulation of experimental teaching plans to the organization and implementation of experimental teaching activities, to the evaluation of experimental teaching and feedback of problems, can be smooth and effective.

\subsection{Promote the Overall Improvement of the Quality of Personnel Training}

Through the comprehensive reform of the experimental teaching system, an experimental teaching platform for the cultivation of railway engineering international students has been established, so that students can not only firmly grasp theoretical knowledge during the school, but also have extensive contact with engineering practice, so as to achieve the integration of theory and experiment. The combination of extracurriculars has improved students' engineering experiment ability and employment competitiveness. At the same time, through reform, more attention has been paid to the cultivation of college students' innovative thinking, innovative methods and innovative abilities, so that the students' knowledge, abilities and qualities have been developed in a coordinated manner, which has improved the students' sustainable development ability and benefited the students for life.

\section{Conclusion}

In summary, the railway engineering specialty shows a strong research nature, and how to solve the problem of cultivating the international students of the railway engineering specialty is a core problem that the railway engineering specialty of colleges and universities needs to solve at this stage. Therefore, educators of railway engineering majors in colleges and universities must innovate their ideology and concepts, improve the clear under- 
standing of the necessity of training talents for research, strengthen the in-depth analysis of the major problems in the experimental teaching of railway engineering under the cultivation of international students, and clarify the talents of railway engineering cultivation goals, promote the reform of teaching courses and teaching systems, strengthen the innovation ability, experimental ability and engineering awareness training, etc., actively promote the smooth development of railway engineering professional research personnel training, and provide more vital forces for The whole world's social development. Through reform, an experimental teaching system for the railway engineering specialty was constructed, that is, the experimental course system and content system determined by the international students training program were taken as the core, the construction of teachers, experimental facilities, practice bases and other conditions was based, and the system construction and operation organization construction, which is an organic whole composed of four elements for protection. It is closely integrated with the theoretical teaching system and relatively independent. It guarantees the realization of the goal of international students training. Through reforms, it is possible to integrate and optimize the experimental teaching links, content, methods and evaluation system, and build a "gradual experiment-professional experiment-comprehensive experiment" progressive gradient experiment teaching system. Form a benign pattern of collaborative training of laboratories, practice bases and scientific research bases, mutual promotion of teaching and scientific research, and effectively promote the improvement of students' experimental innovation ability.

\section{Acknowledgment}

The research is financially supported byHunan Excellent Postgraduate Teaching Team (Training Engineering Teaching Team) (Xiang Jiao Tong [2019] No. 370); Civil Engineering National Virtual Simulation Experimental Teaching Center (Central South University) Open Project (202001); Education and Teaching Reform Project of Central South University (2020jy063 ); Graduate Course Ideological and Political Construction Project of Central South University (2020YJSKSA32), which is gratefully acknowledged by the authors.

\section{References}

[1] Wang Weidong, Xie Youjun, Lou Ping, et al. Exploration and practice of the cultivation of engineering talents in the rail transit industry [J]. Higher Education in Architecture, 2018, 27 (06): 36-43.

[2] Zhong Hua, Han Botang. Practical teaching paradigm and application of innovative and research talent cultivation [J]. Teaching in Chinese University, 2012 (03): 39-42.

[3] Sun Shenghe. Some experience of international students training $[\mathrm{J}]$. Degree and Postgraduate Education,2008 (08):1-3.

[4] Kang Zhuang, Zhou Shunhua. Discussion on the team training model of engineering graduatesTake the railway engineering major of Tongji University as an example [J]. Degree and Graduate Education, 2013 (01): 19-22.

[5] Wang Bin, Cai Xiaopei, Yang Na. Achievements-oriented railway engineering professional training program revision $[\mathrm{J}]$. Higher Architectural Education, 2018,27 (05): 41-46.

[6] Wang Wei, Xiang Jie, Wang Weidong. Research on Open Classroom Teaching in Colleges and Universities__Practical Questionnaire Analysis Based on Students' Perspective [J]. Modern University Education, 2018 (02): 96-102.

[7] Wang Weidong, Peng Limin, Yu Zhiwu, et al. Research and practice of the diversified training model of civil engineering specialty talents [J]. Higher Engineering Education Research, 2015 (01): 144-148 + 160.

[8] Cheng Tao, Ding Yifei, Feng Ping, et al. Research and Practice Based on international students training Model__ Taking the " $3+1+$ X" Urban Rail Transit international students training as an Example [J]. Chinese Universities Technology, 2017 (S1): 67-70.

[9] Pei Ruijiang, Liu Yanhong. Research on the innovation of rail transportation international students training at different levels $[\mathrm{J}]$. Urban Express Rail Transit, 2016, 29 (06): 54-59.

[10] Tian Mao, Zhu Kefei. Research on Urban Rail Transit international students training System $[\mathrm{J}]$. Modern Urban Rail Transit, 2016 (06): 87-91. 